\title{
Case Study for Planning of Cell Production System
}

\author{
Zvonko Kremljak
}
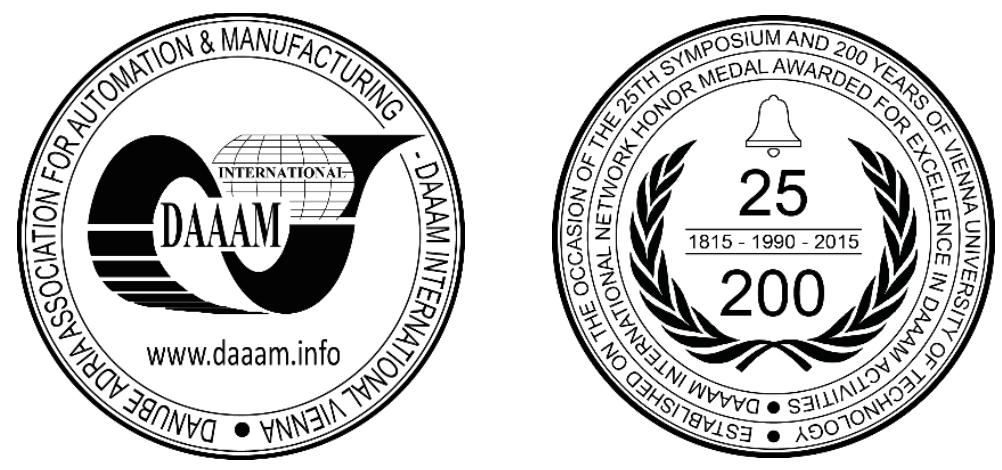

This Publication has to be referred as: Kremljak, Z[vonko] (2018). Case Study for Planning of Cell Production System, Proceedings of the 29th DAAAM International Symposium, pp.0125-0132, B. Katalinic (Ed.), Published by DAAAM International, ISBN 978-3-902734-20-4, ISSN 1726-9679, Vienna, Austria DOI: $10.2507 / 29$ th.daaam.proceedings.017

\begin{abstract}
Two key decisions in designing cell production systems are cell formation and layout design problems. In the cell formation problem, machine groups and part families are determined while in the facility layout problem the location of each machine in each cell and the location of each cell are decided. In the paper the configuration model of the cell is presented on the specific data sets of the applied schedule. The model evaluated the project, which was implemented for planning of the production process and the capacities of the local manufacturer of hydraulic equipment. The data were taken into account in 120 parts with 177 operations. Most of these operations were carried out on CNC machining centres and turning centres. Our development model was based on operation due to the lack of formal costs and benefits in the traditional cell production. The results show that the solution with 25 cells was the lowest total cost alternative.
\end{abstract}

Keywords: cell production; grouping; genetic algorithm; cost model

\section{Introduction}

Cellular manufacturing (cell production) is the cornerstone of many modern flexible manufacturing techniques, taking advantage of the similarities between parts in order to decrease the complexity of the design and manufacturing life cycle. Group technology is an essential tool for developing each cell production system. The essence of the ratio data in cell production systems has rarely been correctly emphasized since past few decades of research and study. The grouping of parts and machines into manufacturing cells with the objective to improve grouping efficacy is the prime focus of cell formation problem. Cell formation is the first and the most important problem in designing cell production systems. Due to its non-polynomial (NP) nature, various heuristic and metaheuristic algorithms have been proposed to solve cell formation problem, based on the grouping efficacy index, including methods such as simulated annealing, tabu search, genetic algorithms, variable neighbourhood search, and water flow-like algorithms. However, most of the proposed models and algorithms have more or fewer drawbacks on the issues with real-life situations.

\subsection{Literature review}

In the literature review the most important publications in the field of cell production systems from the last decade are included. 
Part-machine grouping problem is the key step in cell production aiming at grouping parts with similar processing requirements or similar design features into part families and by grouping machines into cells associated to these families. Different techniques for solving it are based on heuristics. Boutsinas proposed a new approach for solving the problem, which is based on bi-clustering. Empirical results demonstrate the efficiency and accuracy of the proposed technique [1].

The paper, written by Arora et al. aims to discuss various cell formation techniques and highlights the significant research work done in past over the years and attempts to points out the gap in research [2]. Although the proposed mathematical models can produce the best solutions for small sized problems within reasonable times, they are inadequate to produce the best solutions for large sized real life cases due to the NP-hard nature of the problem. In the study of Sahin and Alpay, a genetic algorithm has been proposed for the problem of part-machine-worker cell formation [3]. The experimental results show that the proposed genetic algorithm can produce optimal solutions for small sized problems and optimal or near-optimal solutions for large sized problems within reasonable times.

Liu et al. proposed a mathematical model that incorporates multiple key real-life production factors simultaneously (production volume, batch size, alternative process routings and perfect coefficient of each routing, cell size, unit cost of intercell/intracell movements, and path coefficient of material flows). They developed and tested a special heuristic algorithm, useful for cell design in both quality and speed [4].

A comprehensive mathematical model for the design of cell production systems based on tooling requirements of the parts and tooling available on the machines was proposed by Defersha and Chen. The model incorporates dynamic cell configuration, alternative routings, lot splitting, sequence of operations, multiple units of identical machines, machine capacity, workload balancing among cells, operation cost, cost of subcontracting part processing, tool consumption cost, setup cost, cell size limits, and machine adjacency constraints [5]. Shiyas and Pillai presented an algorithm for the design of manufacturing cells and part families [6]. The objective of this algorithm is the maximisation of grouping efficacy, which is one of the most widely used measures of quality for cellular configurations. Assignment of machines to cells is using genetic algorithm, and part assignment heuristic is based on an effective customised rule.

A comprehensive mathematical model is proposed for designing robust machine cells for dynamic part production in the paper written by Deep and Singh [7]. A genetic algorithm based heuristic is proposed to solve the model for minimization of the overall cost considering various manufacturing aspects such as production volume, multiple process route, machine capacity, material handling and subcontracting part operation. Ghosh et al. attempted to deal with cell formation problem which exploits machine utilization percentage and eliminates the fuzziness on the subject of ratio data [8]. A distinctive technique is adopted based on multi-criteria decision technique with significant modifications which is experimented on test data and compared with published methodology. A novel performance measure is proposed and elaborated analytically to establish its superiority and robustness.

Brusco developed and implemented an iterated local search heuristic that has proved effective for a variety of different combinatorial optimization problems [9]. Computational results for cell formation revealed that the heuristic generally matches the optimal (or best known) solutions for 37 test problems from the literature. Karaulova and Shevtshenko developed a work-cells concept supported by a similarity analysis, production line balancing and production process simulation [10]. Simulation allows setting better time distribution for universal work cells.

Sowmiya et al. proposed a three-stage heuristic to solve the machine-part cell formation problem in which parts have alternative process plans, commonly known as the generalized group technology problem [11]. In the first stage, the best process plan (part route) for each part is selected using the proposed route rank index, a ranking measure calculated from the correlation among the process plans. In the second stage, machine-part cells are identified with an objective to maximize the grouping efficacy.

Zeb et al. presented the hybridization of simulated annealing with genetic algorithm for solving of cell formation problem [12]. The effectiveness of proposed hybrid heuristic algorithm is evaluated through 35 benchmark problems from the literature. The proposed approach achieves the best solutions consistently, within minimum computational time.

Zero-one part-machine incidence matrix generated from route sheet information is commonly presented as input for clustering of parts and machines. The major limitations of this approach lies in the fact that important production factors like operation time, sequence of operations, and lot size of the parts are not accounted for. An attempt has been made in a work of Pandian and Mahapatra to propose a clustering methodology based on adaptive resonance theory for addressing these issues [13].

Despite the popularity of heuristic algorithms, few studies have attempted to develop exact algorithms, such as branch and bound algorithms, applied by Arkat et al. [14]. The proposed branch and bound algorithms and a hybrid genetic algorithm are compared through some numerical examples. The results demonstrate the effectiveness of the modified problem-oriented branch and bound algorithm in solving relatively large size cell formation problems. 
The paper of Zupan et al. shows how clusters of products are designed on the basis of a product line data and how an ideal layout optimization is determined on the basis of the intensity of material flow. Layout optimization of a production cell is based on a combination of Schmigalla modified triangular method and the Schwerdfeger circular process [15].

Flexible manufacturing cells are subject to modelling and simulation to evaluate and correct the production plan using feedback. In the case of highly shared resource contention, deadlock and blocking present an inevitable, unavoidable problem, and corrections may be required for production plans. By using existing Petri net model theories and certain simulation software for model establishment, the structure and scale of the model may vary with changes in the parts, machines, and robots. This results in a cumbersome and complicated model building process. To address this practical problem, a token-oriented Petri net model theory is therefore proposed by Nie et al. [16].

One of the main critique on cell production and its algorithms is their inability to handle dynamic events, especially dynamic changes in part spectrum. Agent-oriented computing provides a marvellous opportunity to handle dynamic problems and to provide effective solutions. A novel agent-based clustering algorithm for part family formation by considering dynamic demand changes has been proposed by Baykasoglu and Gorkemli [17]. Although the proposed algorithm is not an optimisation-based algorithm and its operation is directed to handle dynamic changes in the problem domain through negotiation, they have shown that it has ability to provide very good results which are comparable to the best known solutions.

A single-stage lot/cell production under a Poisson arrival and exponential service in a batch was considered by Matsui [18]. The three economic queuing models of push and pull types are presented, an economic comparison of push versus pull types is considered, and a strategic management/design consideration to the lot production is given. Because of product variety of small electronic products enterprises, their equipment is in condition of half stop production, resulting in the waste of equipment and personnel. Du and Chen gave the mathematical model of Canon cell production to improve production efficiency and reduce the cost, as shown by the simulation results [19].

\section{Planning of operation groups using a genetic algorithm}

For the project, initial identification of the operation and machine cell groups (Table 1) was carried out using the genetic algorithm (GA) specially designed for mechanical groups of components. Genetic algorithms are a group of global optimistic heuristics, stimulated by the process of natural selection in biological systems. Preferably, as a sequence of probable solutions one by one, a population of possible solutions is maintained. Those populations that result in good solutions are matched with each other to result in "children" populations that are assessed in the change.

When generic algorithms are used in cell formations, they deliver excellent results compared to other cell conceptualization techniques, since they have no effect on change. Each solution (represented by a certain number of parts assigned to a cell) is independent of other solutions. Consequently, when very few cells are assigned by the user, a full re-evaluation of the parts of numbers with other parts of numbers is performed. This process allows better grouping of parts than what would be achieved through a hierarchical approach. The practical value of this approach is that with every solution made by GA, the total number of parts assigned to different cells, any potential operation in the solution can vary from one solution to another (more or less parts). This can be seen later in Table 2, which presents a set of solutions generated by GA based on the study data. Generally, it would be considered that the number of parts assigned to the operation plan will be systematically reduced when the number of cells increases. However, the reader can see in Table 3 that the number of parts assigned to the operation area actually increases occasionally, when the solution is based on 21 cells. This result is caused by mutations in the population of solutions that are available for GA, which consistently deliver the same or better results than the unique results from the previous solutions.

\begin{tabular}{|c|lllllllll|}
\hline \multirow{2}{*}{ Machine } & \multicolumn{10}{c|}{ Part } \\
\cline { 2 - 10 }$y$ & 1 & 2 & 3 & 4 & 5 & 6 & 7 & 8 & 9 \\
A & 1 & 1 & 0 & 0 & 0 & 0 & 0 & 0 & 0 \\
B & 1 & 1 & 1 & 0 & 0 & 0 & 0 & 0 & 0 \\
C & 0 & 0 & 0 & 1 & 1 & 1 & 0 & 0 & 0 \\
E & 0 & 0 & 0 & 1 & 0 & 1 & 0 & 0 & 0 \\
F & 0 & 0 & 0 & 0 & 0 & 0 & 1 & 1 & 1 \\
\hline
\end{tabular}

Table 1. Part - Machine matrix

When the parts are grouped, GA uses a health function to evaluate any cellular configuration solution. The health function suggests achieving similarity within the family, and therefore this analysis uses a general group of cellular configurations in combination with the penalty function. 
To calculate the overall grouping of the cellular configuration, the individual group indicators are calculated first for each group (family). Each index attempts to measure the density of the proposed part of the group (family) in order to show fully well-proposed operation and machine group solutions. In the study, the index of association was critical in distinguishing the parts that represented the operational setup from the parts which represented the cells.

For example, let us consider the parts in the three groups (families) assigned to the part - machine (hardware) matrix in Table 1. The individual group's value $\left(g_{k}\right)$ in each family is calculated using (1) below:

$$
g_{k}=\frac{\left(\sum_{j=1}^{p_{k}} \sum_{i=1}^{m_{k}} x_{i j k}\right)-m_{k}}{m_{k}\left(p_{k}-1\right)}
$$

where:

$x_{i j k}=1$, if part $\mathrm{j}$ is processed on the machine $i$ in the cell $k$;

$=0$, otherwise;

$m_{k}-$ number of defined machines in the cell $k$;

$p_{k}-$ number of parts in the cell $k$.

For individual groups of size 1 (one part in an individual group), the base value $g_{k}$ is 1.0 . For parts of family 1 containing parts 1,2 and $3, g_{1}$ shall be calculated as follows: $g_{1}=(5-2) /(2 \times(3-1))=0.75$. Using the same method, $g_{2}=0.75$ and $g_{3}=1.0$.

The joint group value $(G)$ provides a single measure for evaluation of the entire proposed solution. The total grouping is calculated as a weighting average, with the individual group coefficient $\left(g_{k}\right)$ calculated above and all suitable dependents of production, such as the total requirement for parts $\left(d_{k}\right)$ in the group. If the demand depends on the benefit (interest), then the equation for $G$ reads as (2) for all groups $(n)$ :

$$
G=\sum_{k=1}^{n}\left(g_{k} d_{k}\right) /\left(\sum_{k=1}^{n} d_{k}\right)
$$

The health function $(f)$ for GA combines $G$ and the penalty function $C$. The penalty function consists of a normalized number of cells in the solution. It is formulated as in (3):

$$
C=\alpha(n / N)^{\beta}
$$

Through the normalization process, $C$ can be expressed as a value between 0.0 and 1.0. The penalty function serves as a restriction that does not allow the number of cells to increase to a value equal to the total number of parts in the analysis. $\alpha$ and $\beta$ parameters serve as factors that control the growth of penalties. Accordingly, the health function $f$ is represented in (4):

$$
\text { Maximize } f=G-C
$$

GA uses $f$ for systematic comparative solutions. High-level solutions $f$ are placed in the solution population, while those with low values are removed from the solution population.

In the case study data, two values must be assigned depending on the cellular configuration of each solution in a series of solutions: firstly, it is necessary to specify if the operational setup of parts is formed in each part of the cellular solution; and second, it is necessary to determine the point where a pure cell solution appears in the solution set. It is necessary to use the appropriate cost equation for each solution.

To address both experiential values, group indicators are analysed for each solution. Abnormally low group indicators in the solution indicate a weak grouping of the parts that should primarily be produced in the cell. These parts could be best manufactured using a functional setup typical of traditional business production.

\begin{tabular}{|c|c|c|}
\hline Number of (groups) families & Lowest $\boldsymbol{g}$ & Second lowest $\boldsymbol{g}$ \\
\hline 9 & 0.03 & 0.27 \\
\hline 24 & 0.04 & 0.43 \\
\hline 25 & 0.16 & 0.24 \\
\hline
\end{tabular}

Table 2. Example of a group indicator for the case study 
For the case study, the data set was such that abnormally low group indicators (less than 0.1 within the solution) would be defined as parts for a workstation for this solution. Those solutions, which include both workplaces and cellular parts, would represent a mixed cellular environment and would also be accepted accordingly. When all groups (families) within the solution get a group indicator greater than 0.1 , the solution is defined as a pure cellular solution. It should be taken into consideration that the decision to use the break point at 0.1 is arbitrary and highly dependent on the data set in the study.

For example, let us look at Table 2. The table shows the two lowest indicators of permeability in the solutions for 9 , 24 and 25 groups (families). It is considered that for 9 and 24 families the lowest group indicators are less than 0.1 , and these are the families that these indicators represent as operational setup. In addition to this, in family solutions 9 and 24 , the difference between the lowest $g$ and the second lowest $g$ is quite high and will therefore represent a mixed production environment. In a solution with 25 families, the lowest $g$ is 0.16 which is much less different from the second lowest $g$ in this solution. This solution is therefore a transition from a mixed production environment to a pure cellular environment.

\section{Results}

In the existing case study, the GA formulation provides a set of optimal solutions distributed from user-defined 6 partial families to 65 partial families. The cost model task was to determine which of these cellular solutions would be most cost effective and could therefore be chosen for implementation. As it was established, the cost schedule maximum was $400 €$ and the cost schedule minimum was $100 €$.

\begin{tabular}{|c|c|c|c|c|c|c|}
\hline $\begin{array}{l}\text { Number of } \\
\text { cells }\end{array}$ & $\begin{array}{c}\text { Number of } \\
\text { products } \\
\text { manufactured } \\
\text { in a factory } \\
\end{array}$ & $\begin{array}{c}\text { Number of } \\
\text { products } \\
\text { manufactured } \\
\text { in a cell } \\
\end{array}$ & $\begin{array}{c}\text { Total setup } \\
\text { costs }\end{array}$ & $\begin{array}{c}\text { Total } \\
\text { material } \\
\text { costs }\end{array}$ & $\begin{array}{c}\text { Total } \\
\text { investment }\end{array}$ & $\begin{array}{l}\text { TOTAL } \\
\text { costs }\end{array}$ \\
\hline 6 & 69 & 51 & 249800 & 29800 & 115840 & 424400 \\
\hline 7 & 55 & 65 & 217000 & 24120 & 128000 & 401120 \\
\hline 8 & 46 & 74 & 203700 & 21960 & 131200 & 389660 \\
\hline 9 & 42 & 78 & 197000 & 20480 & 133760 & 384680 \\
\hline 10 & 52 & 68 & 236900 & 27480 & 120320 & 414780 \\
\hline 11 & 48 & 72 & 218900 & 22080 & 191360 & 424180 \\
\hline 14 & 35 & 85 & 208700 & 21320 & 150560 & 418820 \\
\hline 16 & 33 & 87 & 210000 & 20280 & 150400 & 418280 \\
\hline 19 & 26 & 94 & 195400 & 17720 & 135168 & 424320 \\
\hline 20 & 20 & 100 & 184400 & 16840 & 152320 & 391640 \\
\hline 21 & 30 & 90 & 199900 & 19000 & 163200 & 422900 \\
\hline 22 & 31 & 89 & 207900 & 19480 & 170880 & 440980 \\
\hline 23 & 19 & 101 & 190200 & 14760 & 183040 & 433760 \\
\hline 24 & 18 & 102 & 184600 & 14240 & 186240 & 431640 \\
\hline 25 & 0 & 120 & 148600 & 9600 & 212800 & 371000 \\
\hline 26 & 0 & 120 & 151800 & 9600 & 212800 & 380600 \\
\hline 30 & 0 & 120 & 156100 & 9600 & 182400 & 393700 \\
\hline 34 & 0 & 120 & 146600 & 9600 & 192000 & 396200 \\
\hline 35 & 0 & 120 & 141880 & 9600 & 193280 & 393100 \\
\hline 38 & 0 & 120 & 115040 & 9600 & 213120 & 419800 \\
\hline 39 & 0 & 120 & 141600 & 9600 & 217600 & 423200 \\
\hline 42 & 0 & 120 & 121900 & 9600 & 238080 & 429096 \\
\hline 53 & 0 & 120 & 91200 & 9600 & 264320 & 431200 \\
\hline 65 & 0 & 120 & 62100 & 9600 & 336000 & 491700 \\
\hline
\end{tabular}

Table 3. Total costs for the study

The shift cost was 100 EUR. The cost of renting machines for the envisaged surface area was estimated at an average of 1000 EUR. Cost factors are graphically presented in Fig. 1 (chart with total setup costs, total material costs, total investment and total costs in relation to the number of production cells). 


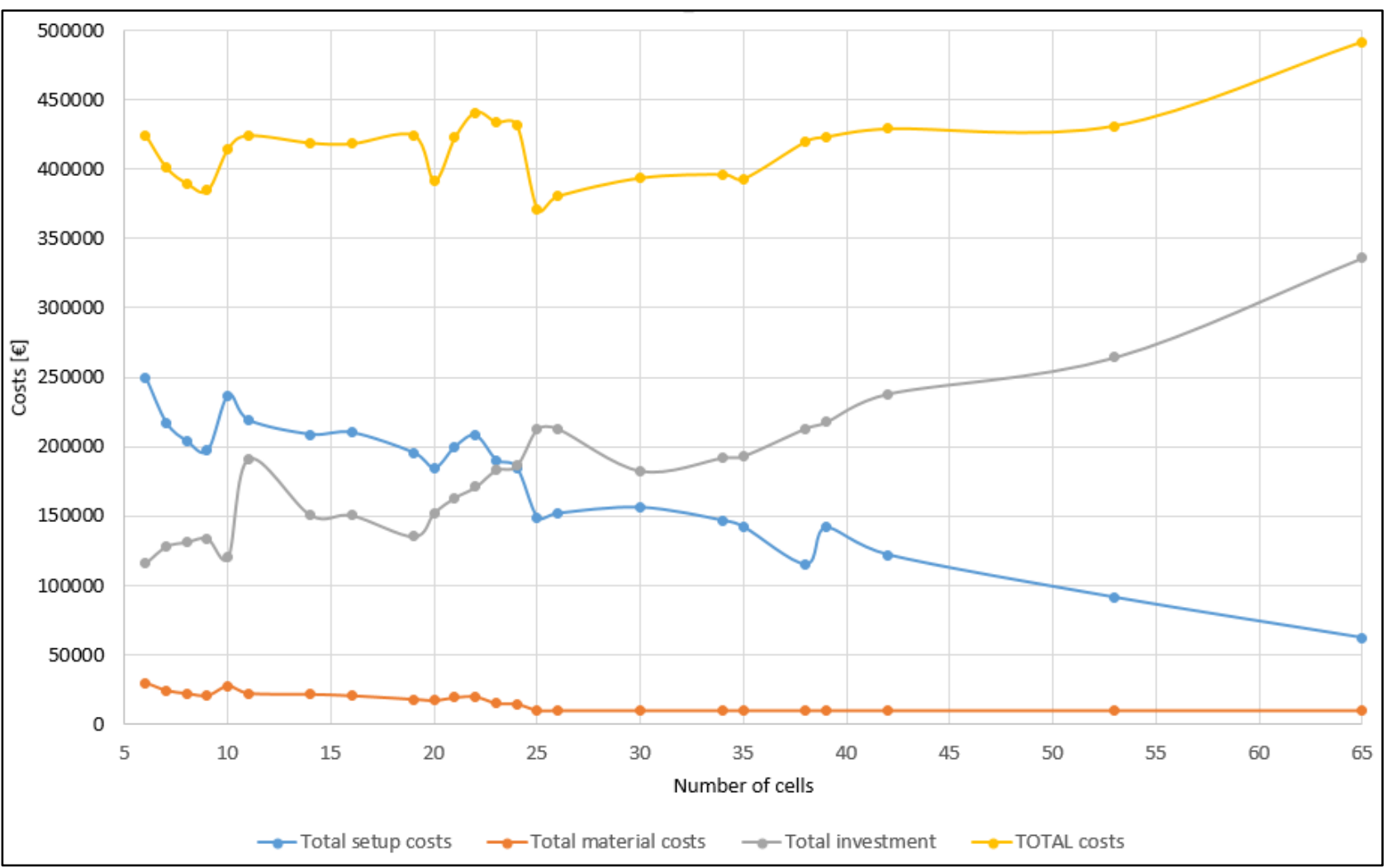

Fig. 1. Total costs in relation to the number of cells

\section{Analysis}

The solution with 25 cells was the lowest total cost alternative (371000 Euro). The next lowest costs alternatives were 26 cells with total costs ( 380600 Euro), and 9 cells with total costs (384680 Euro). Interestingly, an alternative to the lowest total cost appears at a point where all the parts are produced in the cells and the workstation is "eliminated".

Fig. 1 graphically illustrates the impact of the cost factors included in the model and as shown in Table 3, when it examines the total cost of the solution through a number of proposed alternative cellular production configurations. As expected, the total investment cost tended to increase when more and more cells were added. As shown in Fig. 1, there is no sharing of resources between cells, and between cells and working environments. The total cost investment did not increase continuously, but when additional parts were included in the cell because the total investment costs were dependent on the specific processing of the parts in the cell and, consequently, on the machines which were assigned to them. On the contrary, the overall installation cost tended to decline when the cells were assigned. Identical to the total investment cost, it did not continue to decline when new cells were assigned, but it was dependent on the specific relationship between the machine - between the cells and the workstation. The total cost of material flow tended to decrease when the number of cells increased. This cost has reached the peak at the point where all the parts are made in a cell.

The lowest cost solution for this database was most dependent on the total investment cost, as this cost represented the largest proportion of total costs. It follows that the sensitivity analysis was carried out based on the assumption that the cost of renting machines over the planned production area exceeded the $800 €$ per machine. Fig. 2 shows the results of this analysis when the total cost is shown against a number of proposed alternative solutions for average investment costs ranging from $400 €$ to $1600 €$ per machine. When the total investment cost was over $1600 €$ per machine, the best solution was investment in 9 machines.

The results of the analysis clearly showed the importance of incorporating trends that derive from other factors such as WIP, cyclical time, quality, distribution, labour productivity and ethics, that were not directly included in the model, to complement the results obtained from the factors included in the model (setting, material flow, investments). For example, the introduction of 9 cells versus 25 cells would be very attractive. The effort to set up 9 cells would be much smaller than the introduction of 25 cells. Furthermore, it can be performed at a much lower risk. Lastly, the significantly higher investment costs associated with a 25 -cell solution would represent some kind of investment in the future growth potential of the company and the impact that cellular production would have on the increased share of the market. The 
introduction of 9 cells would be a more conservative but risk-averse approach. Factor-related savings, which are not directly involved in the model (WIP, cycle time, quality ...), favour the solutions that contain 25 cells.

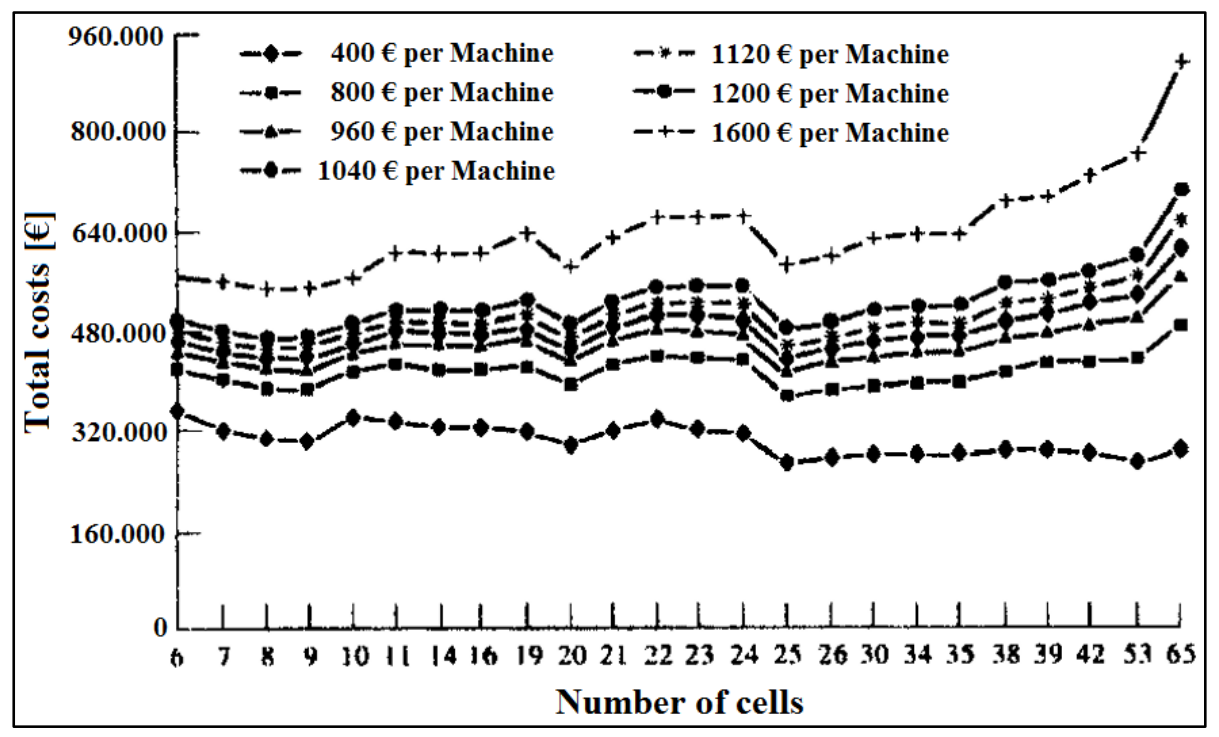

Fig. 2. Influence of machine cost factors included in the model

\section{Conclusion}

Cellular production is based on groups of processes, workers and machines for manufacturing of product (part) families with similar manufacturing characteristics. Families may be based on size, shape, manufacturing or routing requirements, or demand. Once parts have been grouped into families, the next step is to organize the machines needed to perform the processes on these parts into separate cells. Some equipment might have to be duplicated, when a machine is required for more cells. The machines in each cell require only minor adjustments to accommodate product changeovers from one part to the next in the same family. So, the total operation times are reduced and the production system achieves better products' quality and higher flexibility. Appropriate grouping of parts and required machines by comprehensive consideration of factors represented our research problem, because in the previous publications the economic impact of a particular cellular configuration solution was mainly neglected.

In the paper the development of a cell configuration optimization approach, based on an original cost model with application of genetic algorithms, is shown. The presented cost model includes cost factors, which are the most critical and easily set. It evaluates the total costs for each configuration according to investment costs for machines, machine setup costs, and material flow costs, to identify a set of best solutions. The joint group value $(G)$ is used as the crucial single measure for evaluation of the entire proposed solution. The approach is iterative, beginning with the traditional production in process layout and then checking and analysing the solutions with the increasing number of cells. The developed approach is illustrated by a case with 120 parts manufactured within 177 operations (real data of a local production company, which has introduced production cells).

On the basis of the findings, it is clear that the development team needs (additionally) cost data to support the design of cellular production configurations. The optimal case solution shows that 25 cells is the lowest total cost option, where all parts are produced within the cells and none outside the cells in the remaining production facility. With continued increase of the cells the investment costs for additional machines are growing extremely, generating larger total costs.

The cost model described and illustrated in this paper is evolving. The current model includes cost factors that have been perceived as the most critical and which were the most quickly available by manufacturers that have introduced the cellular manufacturing system. The existing model is reliable, easy to use and perceptible, bringing production companies closer to the principles of lean manufacturing.

The future improvement of the model will focus in the first step on integrating and evaluating work-in-process costs into the model and later the translation of other ratios that are currently neglected in the cost model, into estimated values that can be directly included. These alternative solutions can be supported by setting of changes in part processing costs, workplace organization costs, production planning costs, energy costs, parts' cycle time (lead time), work productivity, quality, communication and better commitment of workers (identification with "their" products), basic risk awareness etc. In practice, it is often difficult to collect and maintain accurate statistics on these factors. 


\section{References}

[1] Boutsinas, B. (2013). Machine-part cell formation using biclustering, European Journal of Operational Research, Vol. 230, No. 3, pp. 563-572, ISSN 0377-2217, DOI: 10.1016/j.ejor.2013.05.007

[2] Arora, P. K., Haleem, A. \& Singh, M. K. (2013). Recent development of cellular manufacturing systems, Sadhana - Academy Proceedings in Engineering Sciences, Vol. 38, No. 3, pp. 421-428, ISSN 0256-2499, DOI: $10.1007 / \mathrm{s} 12046-013-0139-\mathrm{z}$

[3] Sahin, Y. B. \& Alpay, S. (2016). A metaheuristic approach for a cubic cell formation problem, Expert Systems with Applications, Vol. 65, pp. 40-51, ISSN 0957-4174, DOI: 10.1016/j.eswa.2016.08.034

[4] Liu, C. G., Yin, Y., Yasuda, K. \& Lian, J. (2010). A heuristic algorithm for cell formation problems with consideration of multiple production factors, The International Journal of Advanced Manufacturing Technology, Vol. 46, No. 9-12, pp. 1201-1213, ISSN 0268-3768, DOI: 10.1007/s00170-009-2170-0

[5] Defersha, F. M. \& Chen, M. Y. (2006). A comprehensive mathematical model for the design of cellular manufacturing systems, International Journal of Production Economics, Vol. 103, No. 2, pp. 767-783, ISSN 09255273, DOI: 10.1016/j.ijpe.2005.10.008

[6] Shiyas, C. R. \& Pillai, V. M. (2014). Cellular manufacturing system design using grouping efficacy-based genetic algorithm, International Journal of Production Research, Vol. 52, No. 12, pp. 3504-3517, ISSN 0020-7543, DOI: $10.1080 / 00207543.2013 .871390$

[7] Deep, K. \& Singh, P. K. (2015). Design of robust cellular manufacturing system for dynamic part population considering multiple processing routes using genetic algorithm, Journal of Manufacturing Systems, Vol. 35, pp. 155163, ISSN 0278-6125, DOI: 10.1016/j.jmsy.2014.09.008

[8] Ghosh, T., Doloi, B. \& Dan, P. K. (2017). Utilization-based grouping efficiency and multi-criteria decision approach in designing of manufacturing cells, Proceedings of the Institution of Mechanical Engineers, Part B: Journal of Engineering Manufacture, Vol. 231, No. 3, pp. 505-522, ISSN 0954-4054, DOI: 10.1177/0954405416629583

[9] Brusco, M. J. (2015). An iterated local search heuristic for cell formation, Computers \& Industrial Engineering, Vol. 90, pp. 292-304, ISSN 0360-8352, DOI: 10.1016/j.cie.2015.09.010

[10] Karaulova, T. \& Shevtshenko, E. (2015). Work-cells concept development for high mix low volume market conditions, Procedia Engineering, Vol. 100 (25 ${ }^{\text {th }}$ DAAAM International Symposium on Intelligent Manufacturing and Automation), pp. 90-99, ISSN 1877-7058, DOI: 10.1016/j.proeng.2015.01.346

[11] Sowmiya, N., Srinivasa Gupta, N., Valarmathi, B. \& Ponnambalam, S. G. (2017). CORA - a heuristic approach to machine-part cell formation in the presence of alternative process plans, The International Journal of Advanced Manufacturing Technology, Vol. 91, No. 9-12, pp. 4275-4297, ISSN 0268-3768, DOI: 10.1007/s00170-017-00382

[12] Zeb, A., Khan, M., Khan, N., Tariq, A., Ali, L., Azam, F. \& Jaffery, S. H. I. (2016). Hybridization of simulated annealing with genetic algorithm for cell formation problem, The International Journal of Advanced Manufacturing Technology, Vol. 86, No. 5-8, pp. 2243-2254, ISSN 0268-3768, DOI: 10.1007/s00170-015-8288-3

[13] Pandian, R. S. \& Mahapatra, S. S. (2009). Manufacturing cell formation with production data using neural networks, Computers \& Industrial Engineering, Vol. 56, No. 4, pp. 1340-1347, ISSN 0360-8352, DOI: 10.1016/j.cie.2008.08.003

[14] Arkat, J., Abdollahzadeh, H. \& Ghahve, H. (2012). A new branch and bound algorithm for cell formation problem, Applied Mathematical Modelling, Vol. 36, No. 10, pp. 5091-5100, ISSN 0307-904X, DOI: 10.1016/j.apm.2011.12.047

[15] Zupan, H., Herakovic, N., Zerovnik, J. \& Berlec, T. (2017). Layout optimization of a production cell, International Journal of Simulation Modelling, Vol. 16, No. 4, pp. 603-616, ISSN 1726-4529, DOI: 10.2507/IJSIMM16(4)4.396

[16] Nie, X. D., Chen, X. D. \& Chen, X. (2016). Simulation study of flexible manufacturing cell based on token-oriented Petri net model, International Journal of Simulation Modelling, Vol. 15, No. 3, pp. 566-576, ISSN 1726-4529, DOI: 10.2507/IJSIMM15(3)CO14

[17] Baykasoglu, A. \& Gorkemli, L. (2015). Agent-based dynamic part family formation for cellular manufacturing applications, International Journal of Production Research, Vol. 53, No. 3, pp. 774-792, ISSN 0020-7543, DOI: $10.1080 / 00207543.2014 .924634$

[18] Matsui, M. (2002). A queuing/management consideration on Japanese production systems, Production Planning \& Control, Vol. 13, No. 8, pp. 688-701, ISSN 0953-7287, DOI: $10.1080 / 0953728021000058884$

[19] Du, Y. \& Chen, Q. X. (2012). The model and simulation of SMT production, Applied Mechanics and Materials, Vols. 217-219, pp. 1493-1496, ISSN 1662-7482, DOI: 10.4028/www.scientific.net/AMM.217-219.1493 